\title{
IS THERE A SHALLOW LOGICAL REFUTATION OF THE ONTOLOGICAL ARGUMENT? ${ }^{1}$
}

\author{
YUJIN NAGASAWA
}

University of Birmingham

\begin{abstract}
The beauty of Anselm's ontological argument is, I believe, that no matter how one approaches it, one cannot refute it without making a significant metaphysical assumption, one that is likely to be contentious in its own right. Peter Millican $(2004,2007)$ disagrees. He introduces an objection according to which one can refute the argument merely by analysing its shallow logical details, without making any significant metaphysical assumption. He maintains, moreover, that his objection does not depend on a specific reading of the relevant Anselmian text; in fact, Millican claims that his objection is applicable to every version of the ontological argument. In this paper, I argue that Millican's objection does not succeed, because, contrary to what he says, in order to justify his objection he does have to make a deep metaphysical assumption and rely on a specific reading of Anselm's text.
\end{abstract}

\section{INTRODUCTION}

In his 2004 paper, Peter Millican formulates the ontological argument found in Anselm's Proslogion and develops a radically new objection to it. In my 2007 paper I argue for the following three claims: (i) it is not obvious that Anselm's text supports Millican's formulation of the ontological argument, (ii) there is an alternative formulation of the argument that is consistent with the text, and (iii) the alternative formulation is not vulnerable to Millican's objection. In his 2007 paper Millican argues that the alternative formulation fails, for more or less the same reason that the original formulation fails. The aim of this paper is to raise a difficulty

${ }^{1}$ This paper was read at a meeting of the Joseph Butler Society at Oriel College, Oxford. I would like to thank members of the society for helpful comments and useful suggestions. I would also like to thank Peter Millican for our exchange on the ontological argument. 
with Millican's attempt to refute the alternative formulation. Although this paper results from my exchange with Millican over the last couple of years it does not presuppose any familiarity with the earlier papers.

One might claim that it is not very important to examine Millican's particular objection to the ontological argument because there is a general consensus among philosophers that the argument fails one way or the other anyway. I disagree. The beauty of the ontological argument is, I believe, that no matter how one approaches it one cannot, if it is formulated properly, refute it without making a significant metaphysical assumption. Such an assumption seems likely to be contentious independently of the debate over the argument itself. In other words, there can be no objection to the ontological argument that is obviously and uncontroversially successful; this is indeed what the history of the debate on the argument seems to have proved for 930-odd years. It is important to determine the cogency of Millican's objection precisely because he diametrically opposes such a view. According to Millican, we can refute the ontological argument with relative ease, merely by analysing its shallow logical structure without making any significant metaphysical assumption. Millican says, moreover, that his objection does not depend on a specific reading of the relevant Anselmian text; in fact, he claims that his objection is applicable to all versions of the ontological argument.

In what follows, I argue that Millican's objection to the ontological argument does not succeed because in order to advance his objection Millican does, ironically, have to make a deep metaphysical assumption and rely on a specific reading of Anselm's text.

\section{TWO DISTINCTIVE FEATURES OF MILLICAN'S OBJECTION}

Millican's objection to the ontological argument has two distinctive features. The first is that, unlike other existing objections, his objection is meant to undermine the argument without questioning any of Anselm's implicit or explicit metaphysical assumptions. Consider, for example, the following two well-known objections that Millican contrasts with his own objection.

The comparison difficulty: There seems to be something logically odd about purporting to compare something that exists only 'in the mind' with something existing in reality. Therefore Anselm's premise ... which crucially depends on the possibility of doing so, is dubious (Millican 2004, p. 443). 
The Kantian dogma ('existence is not a predicate'): As Kant famously argued (anticipated to a significant extent by Gassendi and Hume), it seems dubious to consider something's existence as a property that characterizes it, and hence as a factor that can contribute to the assessment of its greatness. Rather, its existence seems to be something presupposed if it is to have any properties at all (Millican 2004, p. 443).

Millican thinks that such objections as the comparison difficulty and the Kantian dogma are at best ineffective because in order to defend them one has to commit oneself to controversial, deep metaphysical assumptions such as that the greatness of an existent entity and the greatness of a nonexistent entity are not comparable or that existence is not a property that characterizes its possessor. He maintains that his objection is better because it sets aside any metaphysical assumptions and questions only shallow logical details of the ontological argument. Thus, as I explain below, he tries to construct an objection by appealing, on behalf of Anselm, to 'a radically non-Kantian theory of existence-independent "natures" within which [Anselm's] argument can be framed so as to resist the standard objections' and 'identify a hitherto unremarked flaw in [Anselm's] reasoning which not only invalidates the argument in its original form, but which also, unlike those standard objections, operates at a level which makes it ineradicable by any plausible reformulation' (Millican 2004, p. 438). In using the term 'nature' Millican refers to an existence-independent entity and speaks of a nature as 'instantiated' if such an entity exists in reality.

The second unique feature of Millican's objection is that it purports to be neutral with respect to the interpretation of the relevant text, even though it might appear otherwise initially. Consider a key sentence in Chapter 2 of Anselm's Proslogion. M. J. Charlesworth translates the sentence as follows:

(Translation 1) [I]f [God] exists solely in the mind even, it can be thought to exist in reality also, which is greater. (Anselm 1077-1078, p. 117)

This translation suggests that Anselm compares two beings: God existing only in the mind and God existing in the mind as well as in reality. Millican (2004) claims, however, that this is a mistranslation. He says that it should, rather, be translated as follows:

(Translation 2) [I]f [God] exists solely in the mind, something that is greater can be thought to exist in reality also. (Millican 2004, p. 439) 
Millican says that Translation 2, which can fairly be regarded as a nonstandard interpretation, ${ }^{2}$ implies that, contrary to what Translation 1 says, Anselm compares God existing only in the mind and something else (i.e., something that isn't God) existing in the mind as well as in reality. However, Millican emphasises that he is 'undogmatic about the interpretative issue' and 'insist[s on his objection] on a philosophical point' (Millican 2007, p. 1041). In fact he thinks that 'objections in a similar spirit could be made against all versions of the [o]ntological [a]rgument', not just the specific version that Millican formulates on the basis of his non-standard reading of Anselm's text (p. 1043).

\section{MILLICAN'S THEORY OF NATURE}

Millican claims that in order to construct a successful objection to the ontological argument it is helpful to introduce a theory that enables 'reference to be made to an "entity" (such as God) without presupposing either its existence or its non-existence' (p. 449). Millican uses the term 'nature' to denote an existence-independent entity and speaks of a nature as 'instantiated' if such an entity exists in reality.

According to Millican's theory of natures, the nature of, for example, Laika, i.e., the Russian space dog, can be expressed as follows:

$<$ Laika $>$ : <first dog to be sent into space $>$

In general, the first set of angle brackets encloses the name of a nature and the second set encloses at least one of the most significant properties of that nature. Following this format, the natures of Lassie, i.e., the television dog, and Kings Alfred and Arthur, i.e., British heroes, can be expressed as follows:

$<$ Lassie $>$ : $<$ dog, catches villains, rescues victims, star of film and TV $>$

$<$ Alfred $>$ : $<$ King of England, defeated the Danes, translated Boethius $>$ $<$ Arthur $>$ : $<$ saintly and heroic king, kept a court of knights, sought the Holy Grail>

${ }^{2}$ See, for example, Graham Oppy (2008, pp. 114-115). Oppy surveys five recent formulations of the ontological argument provided by Millican, Timothy Chambers, Jordan Howard Sobel, Nicholas Everitt, and Brian Leftow. Among these five interpreters, only Millican formulates the argument in terms of the comparison of greatness between God existing only in the mind and something else existing both in the mind and in reality, instead of the comparison of greatness between God existing only in the mind and God existing both in the mind and in reality. 
Millican maintains that Anselm subscribes implicitly to this theory of natures, which enables him to rank them on the basis of their greatness. According to Millican's interpretation, Anselm thinks that 'among the various criteria for greatness (power, wisdom, goodness, etc.) real existence [or instantiation] "trumps" all others, so that any nature which has a real archetype, however lowly its characteristic properties may be, will on that account alone be greater than any nature, however impressively characterized, which does not' (p. 451). This means that, according to Millican's interpretation, Anselm endorses the following principle:

The Principle of the Superiority of Existence (PSE): Any nature that is instantiated is greater than any nature that is not instantiated (or any nature that is conceived only in the mind).

Suppose that Lassie is more courageous and smarter than Laika. According to PSE, however, $<$ Lassie $>$ is less great than $<$ Laika $>$ because it is not, unlike $<$ Laika $>$, instantiated. It is controversial whether or not King Arthur really existed; that is, whether or not $<$ Arthur $>$ was instantiated. If $<$ Arthur $>$ was instantiated, then it is the greatest among the above four natures, for its existence immediately defeats $<$ Lassie $>$ and its other great-making properties defeat $<$ Laika $>$ and $<$ Alfred $>$. On the other hand, if $<$ Arthur $>$ was not instantiated, then it is not as great as $<$ Alfred $>$ or even $<$ Laika $>$. It is only greater than $<$ Lassie $>$.

Now the nature of God can be expressed as follows:

$<$ God $>$ : <omniperfect, creator of the universe $>$

Omniperfection includes all divine properties, such as omniscience, omnipotence and moral perfection. If $<\mathrm{God}>$ is instantiated, then it is greater than the above four natures, or indeed any natures at all, except $<$ God $>$ itself. $^{3}$ On the other hand, if $<\operatorname{God}>$ is not instantiated, then it is not even as great as <Laika $>$; it is only greater than all other uninstantiated natures such as $<$ Lassie $>$.

Using the concept of natures, Millican presents his interpretation of the ontological argument as follows (pp. 457-458):

(1) The phrase 'a-nature-than-which-no-greater-nature-can-be-thought' is clearly understood by the Fool, and apparently makes sense.

(2) Hence we can take the phrase 'a-nature-than-which-no-greaternature-can-be-thought' as successfully denoting some specific nature.

${ }^{3}$ Here I assume that no other nature is as great as $<\mathrm{God}>$. 
(3) A nature which is instantiated in reality is greater than one which is not.

(4) So if a-nature-than-which-no-greater-nature-can-be-thought were not instantiated in reality, then it would be possible to think of a nature that is greater (for example, any nature that is in fact instantiated in reality). (5) But this would be a contradiction, since it is obviously impossible to think of a nature that is greater than a-nature-than-which-no-greaternature-can-be-thought.

(6) Therefore a-nature-than-which-no-greater-nature-can-be-thought must indeed be instantiated in reality.

Notice that premise (3) is equivalent to PSE. On the basis of the above interpretation and the theory of natures, Millican provides a unique objection to the ontological argument. Whether or not it is legitimate to reformulate the ontological argument in terms of natures, as Millican does, is a matter of further debate. In this paper, however, I assume, in favour of Millican, that it is legitimate.

\section{MILLICAN'S OBJECTION TO THE ONTOLOGICAL ARGUMENT}

Millican's objection is concerned with the most crucial phrase in Anselm's ontological argument, namely, 'a-nature-than-which-no-greater-naturecan-be-thought', which appears in premises (1), (2), (4) and (5). Millican maintains that there are four possible interpretations of this phrase:

(i) A nature that is so great that no nature is greater

(ii) A nature that can be thought so great that no nature can be thought greater

(iii) A nature that is so great that no nature can be thought greater

(iv) A nature that can be thought so great that no nature is greater

Now assume that the following is the greatest instantiated nondivine nature: $<$ Aurelius $>$ : <absolute Emperor of the Roman Empire, wise, just, beneficent $>$

On this assumption, atheists would think that $<$ Aurelius $>$ is the greatest instantiated nature simpliciter, and a fortiori the greatest nature simpliciter. Millican argues that none of the above four possible interpretations of the phrase enables Anselm to convince atheists to hold that $<\mathrm{God}>$, rather than $<$ Aurelius $>$, is the greatest nature.

Consider each of (i) through (iv). Given PSE the following observations can be made: 
Phrase (i) denotes an instantiated nature that is so great that no instantiated nature is greater. Atheists would think that, on this interpretation, the phrase 'a-nature-than-which-no-greater-naturecan-be-thought' refers to <Aurelius $>$ rather than $<$ God $>$. Here, the ontological argument yields the trivial conclusion that the greatest nature is instantiated, i.e., that there exists the greatest existent being.

Phrase (ii) denotes a nature such that if it exists, it is so great that no nature can possibly be thought greater. In this case, the phrase refers successfully to $<$ God $>$ and the ontological argument runs smoothly through premise (4). However, it fails at premise (5), according to which it is impossible to think of a nature that is greater than a-naturethan-which-no-greater-nature-can-be-thought. Given PSE, atheists would claim that it is possible to think of a nature that is greater than a-nature-than-which-no-greater-nature-can-be-thought; namely, any nature that is instantiated (e.g., <Laika $>$, <Alfred $>$, <Aurelius $>$, etc.). From the atheistic point of view, they are greater simply because, unlike $<$ God $>$, they are instantiated.

(iii) denotes an instantiated nature that is so great that no nature can possibly be thought greater. Atheists would not think of this phrase as denoting any nature at all, because there is no such nature unless $<\mathrm{God}>$ is instantiated. On this interpretation, premise (2), i.e., that we can take the phrase 'a-nature-than-which-no-greater-nature-can-bethought' as successfully denoting some specific nature, is unwarranted.

(iv) denotes a nature such that if it is instantiated it is so great that no instantiated nature is greater. In this case, the phrase could refer to $<$ God $>$. ${ }^{4}$ However, the ontological argument fails, again, at premise (5) because, given PSE, it is possible for atheists to think of a nature that is greater than $\langle\mathrm{God}>$, namely, instantiated natures, such as $<$ Laika $>$, $<$ Alfred $>$ and $<$ Aurelius $>$.

Therefore, Millican concludes that Anselm's ontological argument fails to prove the existence of God. ${ }^{5}$

${ }^{4}$ Here the phrase can refer to the nature of any uninstantiated being that is greater than the natures of all instantiated beings. $<$ God $>$ falls into this category but the phrase could also refer to other natures that are not as great as $<\mathrm{God}>$. For example, it could refer to the nature of a being that is just like Aurelius but slightly more powerful.

${ }^{5}$ In addition to this main objection, Millican introduces a supplementary objection, which appeals to a Gaunilo-type parody argument (pp. 459-463). According to the objection, there must be something wrong with Anselm's reasoning because we can 


\section{THE ALTERNATIVE FORMULATION OF THE ONTOLOGICAL ARGUMENT}

In my 2007 paper I introduce the following alternative formulation of the ontological argument, which is consistent with the relevant Anselmian text. More specifically, it is consistent with both Translations 1 and 2 above (Nagasawa, 2007, pp. 1035-1036):

(1) The phrase 'a-nature-than-which-no-greater-nature-can-bethought' is clearly understood by the Fool, and apparently makes sense. (2) Hence we can take the phrase 'a-nature-than-which-no-greaternature-can-be-thought' as successfully denoting some specific nature. (3') A-nature-than-which-no-greater-nature-can-be-thought that is instantiated in reality is greater than a-nature-than-which-no-greaternature-can-be-thought that is conceived only in the mind (because existence is a great-making property).

(4') So if a-nature-than-which-no-greater-nature-can-be-thought were not instantiated in reality, then it would be possible to think of a nature that is greater; namely, a-nature-than-which-no-greaternature-can-be-thought that is instantiated in reality.

(5) But this would be a contradiction, since it is obviously impossible to think of a nature that is greater than a-nature-thanwhich-no-greater-nature-can-be-thought.

(6) Therefore a-nature-than-which-no-greater-nature-can-be-thought must indeed be instantiated in reality.

I maintain that this formulation of the ontological argument is not vulnerable to Millican's objection. Premises (1) and (2) say that, whether or not theism is true, the phrase 'a-nature-than-which-no-greater-naturecan-be-thought' can be understood by anyone and, hence, the phrase denotes a specific nature, irrespective of its existencein reality. In particular, given that the phrase is interpreted as a nature that can be thought so great that no nature can be thought greater (interpretation (ii) above), it successfully denotes $<$ God $>$. Premise (3') says that a-nature-than-whichno-greater-nature-can-be-thought that is instantiated in reality is greater than a-nature-than-which-no-greater-nature-can-be-thought that is

construct, from the ontological argument, a parallel argument that yields the absurd conclusion that 'AntiGod' exists, where AntiGod is a being that is almost identical to God, except that, instead of being morally perfect, it is 'most effectively evil'. The parody objection is interesting because, just like Millican's main objection but unlike all other objections, it tries to refute the ontological argument without making any metaphysical assumptions. See Nagasawa (2010) for a critical assessment of this objection. 
conceived only in the mind. This premise is based on the anti-Kantian assumption that existence is a great-making property. Again, Millican tries not to dispute any deep metaphysical issues in advancing his objection to the ontological argument. Specifically, as we saw in Section 2 , he does not dispute the anti-Kantian assumption. Hence, in order to remain consistent with his own methodology, he cannot reject premise (3'). Premises (4') and (5) say that it would be contradictory if a-naturethan-which-no-greater-nature-can-be-thought were not instantiated in reality because it would then be possible to think of a nature that is greater than a-nature-than-which-no-greater-nature-can-be-thought, namely, the same nature that is instantiated in reality. Notice that the argument no longer fails at (5) because it abandons PSE by replacing (3) with (3'). Given (3') it is indeed impossible for atheists to think of a nature that is greater than a-nature-than-which-no-greater-naturecan-be-thought. The argument concludes that, therefore, a-nature-thanwhich-no-greater-nature-can-be-thought must be instantiated in reality.

\section{MILLICAN'S RESPONSE AND THE ALTERNATIVE FORMULATION}

Millican (2007) agrees with me that the above formulation of the ontological argument does not fail in the exact same way as the original version does. Nevertheless, he maintains that it 'fails in a closely related way' (Millican 2007, p. 1041). He claims, in particular, that it fails not for a deep metaphysical reason but, again, for its shallow logical details. In what follows, however, I argue that Millican's claim is not cogent because, contrary to what he says, in order to apply his objection to the above formulation he does have to rely on a deep metaphysical assumption and a specific reading of Anselm's text.

Millican accepts (1) and (2). He agrees that if we interpret the phrase 'a-nature-than-which-no-greater-nature-can-be-thought' as, as I assume, a nature that can be thought so great that no nature can be thought greater, then the phrase is understood even by atheists and successfully denotes $<$ God $>$. Millican argues, however, that I fail to defend the rest of the argument:

But in [defending the rest of the argument] Nagasawa - just like Anselm - is blurring the distinction between the level of greatness that some nature actually has, and the level of greatness that it can be thought to have. Consider, for example, his initial statement of the claim that 'if there were $<\mathrm{God}>$ that is instantiated in reality and $<\mathrm{God}>$ that 
is conceived only in the mind, then the former would be greater than the latter. This conditional may sound plausible, but in fact it is deeply muddled because its antecedent does not describe any possible situation: the nature $<\mathrm{God}>$ - which Nagasawa takes to be the referent of Anselm's key phrase - is either instantiated in reality or it is not, and it cannot be both. (Millican 2007, p. 1051)

This passage seems to miss my point. Again, the nature $<\mathrm{God}>$ is defined by Millican himself as follows:

$<$ God $>$ : <omniperfect, creator of the universe $>$ (Millican 2004, p. 453) My point quoted in the above passage is that the nature described as <omniperfect, creator of the universe> would be greater if it were instantiated in reality than if it were not. Here existence is treated as a property, so there is nothing contradictory in comparing an omniperfect creator of the universe with the property of being existent and the same being without that property. It is true, as Millican says, that the same being cannot be both existent and non-existent simultaneously, but that is irrelevant to my point.

Millican's response to my argument is more clearly explained in the following passage:

Now with this point in mind look at Nagasawa's step (4'), which says that if $<\operatorname{God}>$ were not instantiated in reality, then it would be possible to think of a nature 'that is greater', namely, $<\operatorname{God}>$ 'that is instantiated in reality ([Millican's] emphasis). But if $<$ God $>$ is not, in fact, instantiated in reality, then it is not possible to think of any nature that in fact achieves this higher level of greatness: thinking of $<\mathrm{God}>$ as instantiated adds nothing to its actual level of greatness. (p. 1052)

This passage suggests that Millican's theory of natures does not allow the comparison of greatness between uninstantiated $\langle x\rangle$ and instantiated $\langle x\rangle$, even though it might allow the comparison of greatness between uninstantiated $\langle x\rangle$ being thought of not existing in reality and uninstantiated $\langle x\rangle$ being thought of existing in reality. Millican thinks that the comparison of greatness between uninstantiated $\langle x\rangle$ and instantiated $\langle x\rangle$ does not make sense because if $\langle x\rangle$ is not instantiated in reality, there is no such thing as $\langle x\rangle$ that is instantiated in reality. That is why he rejects premises (3') and (4') of the alternative formulation, where the argument makes the comparison of greatness between a-nature-than-which-nogreater-nature-can-be-thought that is instantiated in reality and the same nature that is not instantiated in reality. Yet this means that Millican 
commits himself, unconsciously, to a version of the comparison difficulty, which says, as we saw in Section 2, that ' $[\mathrm{t}]$ here seems to be something logically odd about purporting to compare something that exists only "in the mind" with something existing in reality' (Millican 2004, p. 443). Thus, Millican's objection to the alternative formulation is not as metaphysically neutral as he thinks it is. The comparison difficulty, to which Millican does not allow opponents of the ontological argument to commit themselves, is hidden in his own theory of natures. (The version of the comparison difficulty that Millican endorses might be slightly weaker than the standard version introduced in Section 2 of this paper, because while the standard version does not seem to allow the comparison of greatness between any instantiated nature, on the one hand, and any uninstantiated nature, on the other, his version allows the comparison of greatness between instantiated $\langle x\rangle$ and uninstantiated $\langle y\rangle$ provided that $x$ is not identical to $y$. For example, Millican allows the comparison of greatness between instantiated $<$ Aurelius $>$ and uninstantiated $<$ God $>.{ }^{6}$ As I explain below, however, whether or not Millican's comparison difficulty is weaker than the standard version is beside the point.)

There is yet another problem for Millican, which is that his response to the alternative formulation contradicts his own claim that he does not rely on a specific reading of Anselm's text. As I mentioned earlier, the standard reading of the relevant passage in the Proslogion suggests that Anselm compares two beings: God existing only in the mind and God existing both in the mind and in reality, rather than God existing only in the mind and something else existing both in the mind and in reality. If, as Millican says himself, he is 'undogmatic about the interpretative issue' (Millican 2007, p. 1041), he has to be open to the standard reading.

\footnotetext{
${ }^{6}$ Millican's objection to the original formulation of the ontological argument is based on the assumption that Anselm endorses PSE, which, again, says that a nature that is instantiated in reality is greater than one that is not. Millican thinks that we can safely make this assumption because Anselm does not correct Gaunilo's attribution of the following thesis to him: 'if this same being [God] exists in the mind alone, anything that existed also in reality would be greater than this being' (Gaunilo 1078, p. 157). In my 2007 paper I agree with Millican that the thesis that Gaunilo attributes to Anselm is indeed equivalent to PSE. However, if, as Millican seems to think, PSE implicitly assumes that the comparison of greatness is impossible between a nature that is not instantiated in reality and the same nature that is instantiated in reality, then the thesis in question is not equivalent to PSE. The above quote from Gaunilo does not say anything about the impossibility of the comparison of greatness between a nature that is not instantiated in reality and the same nature that is instantiated.
} 
Yet the way in which he responds to the alternative formulation of the ontological argument excludes such a reading; his response does not allow us to make the comparison of greatness between God existing only in the mind and God existing both in the mind and in reality (or $<$ God $>$ that is not instantiated in reality and $<$ God $>$ that is instantiated in reality), despite the fact that it allows the comparison of greatness between God existing only in the mind and God existing in the mind and also being thought of existing in reality.

In sum: Millican's objection to the alternative formulation precludes us from comparing God existing only in the mind and God existing both in the mind and in reality. This entails that his objection fails because it contradicts its own two unique features discussed in Section 2. With respect to the first feature, i.e., purporting not to make any deep metaphysical assumption, it does make such a deep metaphysical assumption as a version of the comparison difficulty. Admittedly the version that Millican holds could be weaker than the original version; one might judge that Millican's is not even a version of the comparison difficulty. That is, however, beside the point. The point is that, contrary to what he believes, Millican commits himself to a deep metaphysical assumption, to which, again, he does not allow opponents of the ontological argument to commit themselves. With respect to the second unique feature, i.e., purporting not to rely on a specific reading of the relevant Anselmian text, Millican's response to the alternative formulation of the ontological argument does rely on a specific, non-standard reading of Anselm's text. Conversely, if Millican does not adopt the non-standard reading, he cannot defend his objection in the first place.

\section{CONCLUSION}

Whether or not the ontological argument ultimately succeeds it seems unlikely that critics can construct a convincing objection which questions only shallow logical details of the argument. Any objection to the argument seems to make, implicitly or explicitly, a significant metaphysical assumption and could also rely on a specific reading of the relevant Anselmian text. Since both the metaphysical assumptions and the specific readings of Anselm's text are all contentious in their own right, there is no refutation of the argument that satisfies the majority of analysts of the argument. The beauty of the ontological argument seems to remain intact even more than 930 years after Anselm introduced it. 


\section{BIBLIOGRAPHY}

Anselm. 1077-1078. Proslogion, trans., M. J. Charlesworth, in Charlesworth (1965), pp. 101-155

Charlesworth, M. J. 1965. St Anselm's Proslogion (Oxford: Clarendon Press)

Gaunilo. 1078. A Reply to the Foregoing by a Certain Writer on Behalf of the Fool, trans., M. J. Charlesworth, in Charlesworth (1965), pp. 156-167

Millican, Peter. 2004. 'The One Fatal Flaw in Anselm's Argument', Mind, 113: 437-476

Millican, Peter. 2007. 'Ontological Arguments and the Superiority of Existence: Reply to Nagasawa', Mind, 116: 1041-1053

Nagasawa. 2007. 'Millican on the Ontological Argument', Mind, 116: 1027-1039

Nagasawa. 2009. 'The Ontological Argument and the Devil', Philosophical Quarterly, 60: 72-91

Oppy, Graham. 2008. 'The Ontological Argument', eds., Paul Copan and Chad Meister, Philosophy of Religion: Classic and Contemporary Issues (Oxford: Blackwell) 